\title{
Propriedades físicas, químicas e mecânicas dos cimentos tipo CPI e CPV obtidos com diferentes proporções com fíler de calcário
}

Physical, chemical and mechanical properties of cements type CPI and CPV obtained with different proportions of clinker with lime filler

Propiedades fisicas, quimicas y mecánicas del cemento tipo CPI y CPV obtenidos con diferentes proporciones de clinquer con filler de cal

Gilson Vicente da Silva

ORCID: https://orcid.org/0000-0002-7192-0950 Itabira Agro Industrial S/A, Brasil E-mail: gilsonvicente@globomail.com

Simone Pereira Taguchi Borges ORCID: https://orcid.org/0000-0002-7192-0950 Universidade Federal Rural do Rio de Janeiro, Brasil E-mail: simoneptb@hotmail.com.br

Audrei Giménez Barañano

ORCID: http://orcid.org/0000-0002-0174-5202

Universidade Federal do Espírito Santo, Brasil E-mail: audrei3@gmail.com

\begin{abstract}
Resumo
Nas últimas décadas, o crescimento da produção de cimento Portland tem se intensificado, dado o crescimento da construção civil. No entanto, as atividades das indústrias cimenteiras são extremamente poluentes e contribuem com uma grande parcela nas emissões de $\mathrm{CO}_{2}$. Tendo o foco mundialmente adotado de aumento das adições nos cimentos Portland com a visão de desenvolvimento de um produto mais sustentável, o objetivo deste trabalho foi identificar o potencial de substituição de parte do clínquer nos cimentos CPI e CPV ARI RS. Foram utilizados dois tipos de calcário com elevado teor de carbonato de cálcio, um com granulometria mais grossa e o outro com granulometria mais fina produzindo, em laboratório, diferentes argamassas. Verificou-se a influência das adições nas características químicas através dos ensaios normatizados (trióxido de enxofre, resíduo insolúvel, perda ao fogo, óxido de magnésio) e nos ensaios físicos resíduo na peneira 75 microns, expansibilidade a quente, consistência da pasta, início e fim de pega. Os resultados obtidos permitiram verificar que, no que diz respeito ao aspecto químico houve um aumento significativo e esperado na perda ao fogo para o grupo de amostras contendo fíler de calcário. Já para os aspectos físicos, constatou-se que existe uma forte relação entre as maiores resistências à compressão e os efeitos físicos proporcionados pela presença de partículas ultrafinas. Das adições, resultaram cimentos com elevadas resistências à compressão para todas as idades tendo em vista a redução de 50\% de clínquer na composição dos cimentos CPI e CPV ARI RS.
\end{abstract}

Palavras-chave: Cimento; Clínquer; Fíler de calcário.

\begin{abstract}
In recent decades, the growth of Portland cement production has intensified, given the growth of civil construction. However, the activities of the cement industries are extremely polluting and contribute a large share of $\mathrm{CO} 2$ emissions. Having adopted the global focus of increasing additions in Portland cements with a view to developing a more sustainable product, the objective of this work was to identify the potential for replacing part of the clinker in CPI and CPV ARI RS cements. Two types of limestone with a high content of calcium carbonate were used, one with a coarser grain size and the other with a finer grain size, producing different mortars in the laboratory. The influence of additions on chemical characteristics was verified through standardized tests (sulfur trioxide, insoluble residue, loss on fire, magnesium oxide) and physical tests on residue in the 75 micron sieve, hot expandability, paste consistency, onset and end of catch. The results obtained allowed us to verify that, with regard to the chemical aspect, there was a significant and expected increase in the loss to fire for the group of samples containing limestone filler. As for the physical aspects, it was found that there is a strong relationship between the higher compressive strengths and the physical effects provided by the presence of ultrafine particles. The additions resulted in cements with high compressive strengths for all ages, considering a 50\% reduction in clinker in the composition of CPI and CPV ARI RS cements.
\end{abstract}

Keywords: Cement; Clinker; Limestone filler. 


\begin{abstract}
Resumen
En las últimas décadas, el crecimiento de la producción de cemento Portland se ha intensificado, dado el crecimiento de la construcción civil. Sin embargo, las actividades de las industrias cementeras son extremadamente contaminantes y contribuyen en gran medida a las emisiones de CO2. Habiendo adoptado el enfoque global de incrementar las adiciones en cementos Portland con miras a desarrollar un producto más sustentable, el objetivo de este trabajo fue identificar el potencial para reemplazar parte del clinker en los cementos CPI y CPV ARI RS. Se utilizaron dos tipos de calizas con alto contenido en carbonato cálcico, una con granulometría más gruesa y otra con granulometría más fina, produciendo diferentes morteros en laboratorio. La influencia de las adiciones en las características químicas se verificó mediante pruebas estandarizadas (trióxido de azufre, residuo insoluble, pérdida al fuego, óxido de magnesio) y pruebas físicas sobre el residuo en el tamiz de 75 micrones, capacidad de expansión en caliente, consistencia de la pasta, inicio y fin de la captura. Los resultados obtenidos permitieron constatar que, en lo que respecta al aspecto químico, hubo un aumento significativo y esperado de las pérdidas por incendio para el grupo de muestras que contenían filler calizo. En cuanto a los aspectos físicos, se encontró que existe una fuerte relación entre las mayores resistencias a la compresión y los efectos físicos proporcionados por la presencia de partículas ultrafinas, especialmente para el grupo CFB. Las adiciones dieron como resultado cementos con altas resistencias a la compresión para todas las edades, considerando una reducción del 50\% del clinker en la composición de los cementos CPI y CPV ARI RS.
\end{abstract}

Palabras clave: Cemento; Clinker; Carbonato de cálcio filler.

\title{
1. Introdução
}

A indústria de construção civil ocupa um importante papel na economia mundial. Dados da Associação Europeia de Cimento (CEMBUREAU, 2019) avaliam que em 2018 havia cerca de 3,99 bilhões de toneladas de cimento no mundo, o que torna um dos produtos mais consumidos no planeta. Acredita-se que no ano 2050, as indústrias produzirão cerca de 6 bilhões de toneladas de cimento no mundo (CEMBUREAU, 2019).

Porém, o processo de queima do calcário para produção do cimento é complexo, dispendioso e contribui com aumento dos gases de efeito estufa (GEE). Esta atividade é responsável por cerca de 7\% das emissões globais (SNIC, 2019).

Diante desta expressiva contribuição, proveniente dos processos de fabricação de cimentos a Agência Internacional de Energia (IEA) e a Iniciativa de Sustentabilidade do Cimento (CSI) do conselho Empresarial Mundial para o desenvolvimento Sustentável (WBSC) se uniram para publicar em 2009 o Roadmap Tecnológico - Transição de baixo carbono da indústria do cimento. O projeto propõe medidas a serem adotadas pelas industrias cimenteira nacionais e internacionais com objetivo de baixar as emissões de gases de efeito estufa em 24\% até 2050 (IEA/WBCSD, 2009).

No que diz respeito ao Brasil, mesmo sendo considerado um dos países com menor emissão por tonelada de cimento, acredita que pode avançar, ainda mais. Com isso, elaborou o seu próprio roteiro de baixo carbono, para contribuir com o objetivo mundial. As principais ambições e diretrizes é reduzir em 33\% das emissões da indústria cimenteira do Brasil até 2050 (International \& Agency, 2011).

Atualmente, a escória de alto forno e cinzas volantes têm sido utilizadas como adições nos cimentos. Porém, expectativas para os próximos anos é que a produção de cimento continue crescendo mais rapidamente que a oferta dessas duas adições, de modo que não haverá quantidade suficiente para atender a demanda da indústria cimenteira (Scrivener, 2014), sendo necessário o estudo de novas adições para a indústria cimenteira.

De acordo com Ramezanianpour et al. (2009) diversos são os benefícios econômicos e ambientais com o aumento da utilização de adições na argamassa de concreto. No caso do fíler de calcário, apresenta moabilidade maior à do clínquer, que contribui para a redução do consumo de energia elétrica nas operações de moagem.

Organizações como Nanocem, composta de parceiros acadêmicos e uma rede de indústrias, pesquisam materiais cimentícios que ajudam a diminuir a porcentagem de clínquer na composição cimentícia. O novo produto chamado $\mathrm{LC}^{3}$ (Limestone Calcined Clay Cement) possui o fíler de calcário e argila calcinada em sua composição, pois o filer de calcário dispensa calcinação e apresenta pegada de $\mathrm{CO}_{2}$ muito baixa, e ainda está disponível em grande quantidade (Nanocem, 2013). 
Neste trabalho foi adicionado ao clínquer várias proporções de fíler de calcário (5-30\%) com duas granulometrias distintas, e avaliado os aspectos físicos, químicos e mecânicos dos cimentos produzidos. O objetivo do estudo foi identificar o potencial de substituição de parte do clínquer nos cimentos CPI e CPV ARI RS, com o intuito de reduzir os impactos ambientais, os custos de processamento e contribuir para um produto mais sustentáveis.

\section{Metodologia}

O clínquer utilizado neste trabalho foi disponibilizado pela indústria cimenteira do grupo Nassau, localizada em Cachoeiro de Itapemirim-ES, e a coleta foi realizada diretamente do galpão de clínquer. O gesso mineral tem origem de RecifePE e foi coletado na baia de armazenamento da Nassau.

Foram utilizados dois tipos de calcário, um com granulometria mais grossa e com elevado teor de carbonato (proveniente da pedreira na região de Monte Líbano-Itaoca, distrito de Cachoeiro de Itapemirim - ES), e o outro com granulometria mais fina e também com elevado teor de carbonato de cálcio (oriundo da empresa de carbonato Provale, localizado em Itaóca - ES). Essas adições foram identificadas como fíler de calcário A e fíler de calcário B, respectivamente.

Para a produção das argamassas foi utilizado areia padrão (do Instituto de Pesquisa Tecnológico do Estado de São Paulo - IPT), com quatro frações granulométricas, atendendo as especificações da ABNT NBR 7214 (2015).

Foram avaliados os aspectos físicos e químicos das matérias primas e dos cimentos produzidos em laboratório conforme a norma ABNT NBR 16697 (2018).

Para a avaliação da resistência à compressão dos cimentos composto por fíler de calcário, adotou a norma da ABNT NBR 7215 (2019), com objetivo de verificar o desempenho mecânico, através da ruptura de corpos de provas cilíndricos produzidos com os cimentos obtidos, realizado o ensaio de resistência à compressão. O Fluxograma do procedimento experimental é mostrado na Figura 1.

Figura 1 - Fluxograma do procedimento experimental.

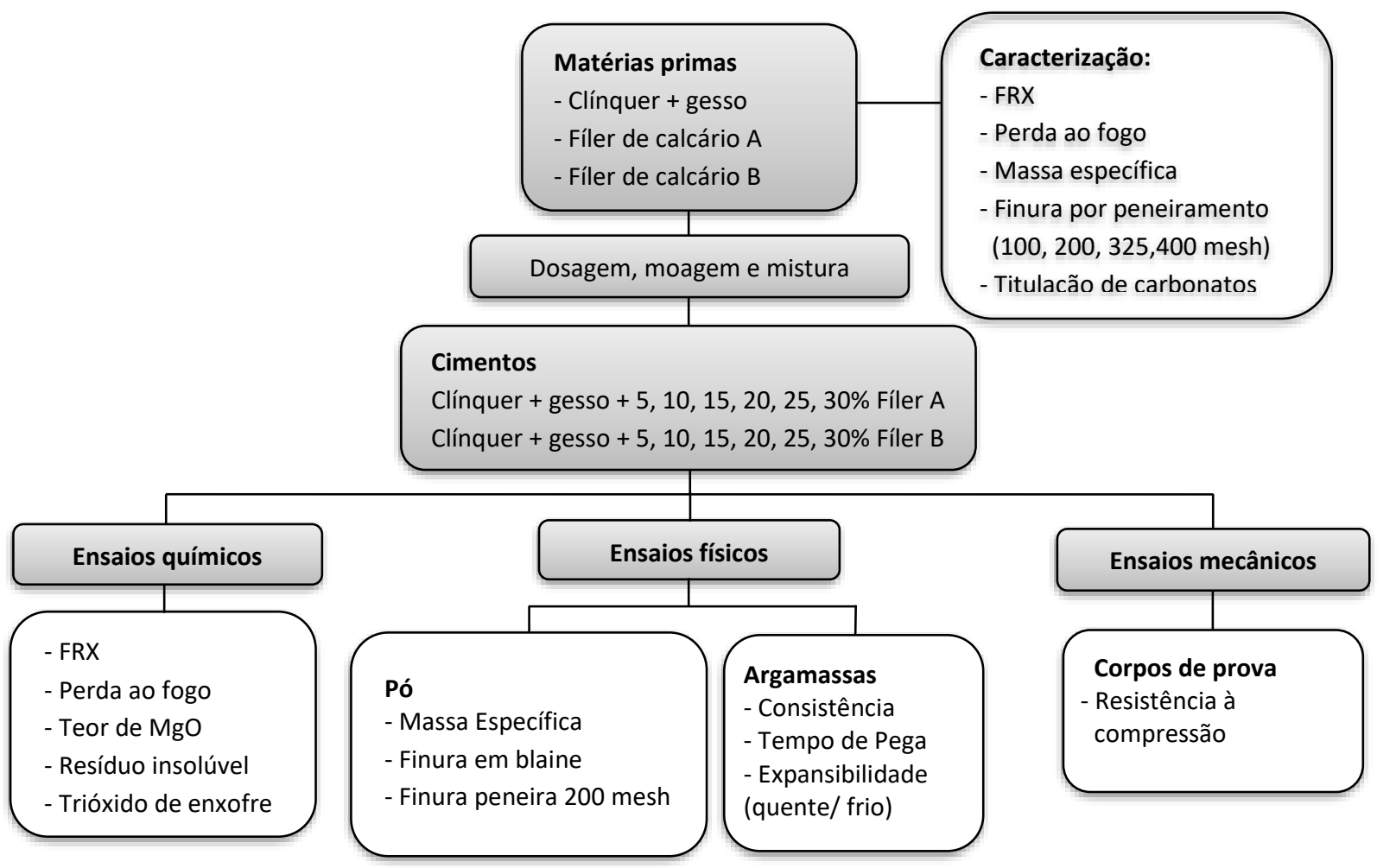

Fonte: Autores. 
O método aplicado no trabalho foi de pesquisa científica do tipo experimental Cervo, Bervian \& Silva (2007), cujo problema central foi propor composição de cimento com menor quantidade de clínquer de forma que mantivesse suas propriedades. As hipóteses estudadas foram acrescentar aditivo de calcário, que tem composição similar ao clinquer, para que este assumisse uma parcela da composição; variar a granulometria para verificar se menor tamanho de partículas promove cimento mais reativo, compensando a menor parcela de clinquer utilizado.

\subsection{Preparação e caracterização das matérias-primas}

A preparação das matérias primas foi conforme Gobbo (2009). Foi coletado $200 \mathrm{~kg}$ de clínquer, realizada a homogeneização e quarteamento, até a obtenção de $100 \mathrm{~kg}$. O clínquer foi fragmentado em britador laboratorial de mandíbula marca Marconi, modelo MA 2015, e moído em moinho de bolas por 100 minutos. Foi coletado $30 \mathrm{~kg}$ de calcário e realizado o mesmo procedimento que o clínquer, porém com tempo de moagem de 45 minutos e sendo previamente seco em estufa micro processada, modelo SX $450 \mathrm{DTME}$, a uma temperatura de $110^{\circ} \mathrm{C}$, por 2 horas. O gesso mineral foi seco em estufa na temperatura de $65^{\circ} \mathrm{C}$ para evitar sua decomposição, e moído em moinho de panelas marca Herzog em porções de $100 \mathrm{~g}$ até atingir a quantidade de $15 \mathrm{~kg}$. Todas as amostras foram passadas na peneira de 200 mesh $(0,074 \mathrm{~mm})$ e misturado no homogeneizador em V, modelo mist.mv.7s.

A proporção dos principais compostos do clínquer (C3S, C2S, C3A e C4AF) foram calculados com base nas Equações 1-4 (Compostos de Bogue), utilizando as respectivas quantidades dos óxidos obtido pelo ensaio de Fluorescência de Raios $\mathrm{X}$ (FRX), sendo $\mathrm{A}=\mathrm{CaO}$ Total; $\mathrm{B}=\mathrm{CaO}$ livre $; \mathrm{C}=\mathrm{SiO}_{2} ; \mathrm{D}=\mathrm{Al}_{2} \mathrm{O}_{3} ; \mathrm{E}=\mathrm{Fe}_{2} \mathrm{O}_{3} ; \mathrm{F}=\mathrm{SO}_{3} ; \mathrm{G}=\mathrm{C}_{3} \mathrm{~S}$.

$$
\begin{aligned}
& \mathbf{C 3 S}=4,07(\mathrm{~A}-\mathrm{B})-(7,60 \mathrm{C}+6,72 \mathrm{D}+1,43 \mathrm{E}+2,85 \mathrm{~F}) \\
& \mathbf{C 2 S}=(2,87 \mathrm{C})-(0,75 \mathrm{G}) \\
& \mathbf{C 3 A}=(2,65 \mathrm{D})-(1,69 \mathrm{E}) \\
& \mathbf{C 4 A F}=3,0432 \mathrm{E}
\end{aligned}
$$

O clínquer, gesso e os fílers de calcário A e B foram previamente fundidos com tetraborato de lítio, e as respectivas pérolas obtidas foram quantificadas quimicamente em FRX da marca Bruker, através da detecção WDS (Wavelenght Dispersive), isto é, dispersão por comprimento de onda.

A perda ao fogo experimental $(P F e$ ) foi determinada conforme a ABNT NBR NM 18 (2012), em forno mufla marca Quimis, modelo Q318S, com alcance de $1000^{\circ} \mathrm{C}$ e taxas de aquecimento de $2,5^{\circ} \mathrm{C} / \mathrm{min}$. Os cadinhos usados foram previamente calcinados por 20 minutos, e a perda ao fogo foi calculada pela Equação 5, onde $M$ é a massa da amostra (g); $M_{l}$ é a massa da amostra mais a massa do cadinho (g); $M_{2}$ é a massa do cadinho mais a massa da amostra após calcinação (g). A perda ao fogo teórica (PFt) foi calculada conforme Equação 6, onde $A=$ filer calcário (\%); $B=$ gipsita (\%); $C=$ clínquer (\%); $P F c=$ Perda ao fogo do clínquer (\%). Para o desenvolvimento do cálculo foi considerada a perda ao fogo teórica do calcário que, acima de 690 ${ }^{\circ} \mathrm{C}$ libera até $44 \%$ de $\mathrm{CO}_{2}$, e a gipsita em temperaturas superiores a $107{ }^{\circ} \mathrm{C}$ liberam $20,91 \%$ de $\mathrm{H}_{2} \mathrm{O}$.

$$
\begin{gathered}
P F e=\frac{M 1-M 2}{M} \cdot 100 \\
P F t=0,44 A+0,2091 B+\frac{C}{100} . P F C
\end{gathered}
$$

A massa específica ( $\rho$ ) das matérias primas foi realizada conforme ABNT NBR 16605 (2017). Para tal, foi preenchido o frasco de Le Chatelier com querosene, colocado em banho termorregulador até atingir o equilíbrio térmico (aproximadamente 
30 minutos), e realizado a leitura inicial da temperatura e do volume do líquido. Pesou-se $60 \mathrm{~g}$ das respectivas amostras e transferiu para o frasco de Le Chatelier, registrando leitura final da temperatura e do nível do líquido. A diferença de temperaturas do banho termorregulador na ocasião das determinações dos volumes do líquido foi inferior a $0,5^{\circ} \mathrm{C}$. A massa específica foi calculada conforme a Equação 7, onde $m$ é a massa da amostra (g); $V F$ é o volume final $\left(\mathrm{cm}^{3}\right) ; V I$ é o volume inicial $\left(\mathrm{cm}^{3}\right)$. As massas específicas foram feitas em triplicata, os resultados dados pela média aritmética dos valores, sendo que não difiram entre si em mais de $0,01 \mathrm{~g} . \mathrm{cm}^{-3}$.

$$
\rho=\frac{m}{(V F-V I)}
$$

Foram realizados os ensaios de finura nas matérias primas e cimentos, conforme a norma NBR NM 11579 (2013), utilizando peneiras de 0,075, 0,045, 0,038 e 0,025 mm, em um peneirador a vácuo marca Emic, modelo PVE-1. Foi utilizada uma balança analítica marca Mettler Toledo, modelo MS204S/A01, com precisão 0,0001 g, e a massa retida (B) foi calculada conforme a Equação 8, na qual $R$ é a massa do cimento retido na peneira $75 \mu \mathrm{m}(\mathrm{g}) ; F=1,09$ referente ao fator de correção da peneira utilizada no ensaio, de acordo com o disposto na ABNT NBR NM ISO 3310-1 (2010) e $M=$ massa inicial do cimento (g).

$$
B=\frac{R \cdot F}{M} \cdot 100
$$

Para a titulação dos carbonatos de cálcio e carbonato de magnésio utilizou-se solução de ácido clorídrico 0,5 molar e hidróxido de sódio 0,25 molar, e os indicadores fenolftaleína e timolftaleína, respectivamente

\subsection{Preparação e caracterização dos cimentos}

Foi adicionado até $30 \%$ de fíler de calcário no clínquer, considerando 5\% de gesso em todas as amostras, conforme mostrado na Tabela 1. A composição de cimento que contém clínquer, $5 \%$ de gesso e fíler de calcário assemelha ao cimento tipo CPI ou CPV-ARI, nos quais foram utilizados para comparação.

A análise quantitativa do óxido de magnésio dos cimentos foi obtida por FRX, e a determinação da perda ao fogo foram realizadas conforme metodologia descrita anteriormente.

A análise de resíduo insolúvel dos cimentos foi realizada conforme ABNT NBR NM 15 (2012). Para tal, foi pesado $1,0000 \mathrm{~g} \pm 0,0100 \mathrm{~g}$ da amostra $(M)$, transferido para um béquer de $250 \mathrm{ml}$, adicionado $25 \mathrm{ml}$ de água e $5 \mathrm{ml}$ de ácido clorídrico $(\mathrm{HCl})$, aquecendo ligeiramente. A solução foi diluída até aproximadamente $50 \mathrm{ml}$ com água quente, aquecida em chapa aquecedora por 15 minutos, filtrada em papel de filtração média e lavada no mínimo 10 vezes com água quente. Reservou o filtrado para determinação do anidrido sulfúrico $\left(\mathrm{SO}_{3}\right)$ e voltou o papel de filtro contento o resíduo insolúvel $(R I)$ para o béquer. 
Tabela 1 - Composição dos cimentos CFA e CFB.

\begin{tabular}{|c|c|c|c|c|}
\hline \multicolumn{5}{|c|}{ Composição dos cimentos $(\%)$} \\
\hline & Clínquer & $\begin{array}{c}\text { Gesso } \\
\text { Mineral }\end{array}$ & $\begin{array}{c}\text { Fíler calcário } \\
\text { A }\end{array}$ & $\begin{array}{c}\text { Fíler calcário } \\
\text { B } \\
\end{array}$ \\
\hline CFA 5 & 90 & 5 & 5 & 0 \\
\hline CFA 10 & 85 & 5 & 10 & 0 \\
\hline CFA 15 & 80 & 5 & 15 & 0 \\
\hline CFA 20 & 75 & 5 & 20 & 0 \\
\hline CFA 25 & 70 & 5 & 25 & 0 \\
\hline CFA 30 & 65 & 5 & 30 & 0 \\
\hline CFB 5 & 90 & 5 & & 5 \\
\hline CFB 10 & 85 & 5 & 0 & 10 \\
\hline CFB 15 & 80 & 5 & 0 & 15 \\
\hline CFB 20 & 75 & 5 & 0 & 20 \\
\hline CFB 25 & 70 & 5 & 0 & 25 \\
\hline CFB 30 & 65 & 5 & 0 & 30 \\
\hline
\end{tabular}

Fonte: Autores.

Adicionou-se $100 \mathrm{~mL}$ de solução $1 \%$ de hidróxido de sódio no béquer contendo o filtro com RI e foi aquecido próximo a ebulição, em chapa aquecedora por 15 minutos, sendo agitado periodicamente. Adicionou-se 3 a 4 gotas de solução a $2 \%$ de indicador vermelho de metila e acidificou com gotas de ácido clorídrico, com 4 gotas de excesso. Filtrou-se a quente com papel de filtração média e lavou com água quente até a eliminação dos cloretos.

Para determinar a porcentagem de resíduo insolúvel, foi colocado o papel filtro contendo o resíduo insolúvel em um cadinho previamente calcinado e pesado $(M 1)$, sendo queimado em um forno mufla a $1000^{\circ} \mathrm{C}$, com taxas de aquecimento de 2,5 ${ }^{\circ} \mathrm{C} /$ min por 45 minutos. O cadinho foi esfriado e novamente pesado (M2), sendo a porcentagem de resíduo insolúvel calculada pela Equação 9.

$$
R . I=\frac{M 2-M 1}{M} \cdot 100
$$

A porcentagem de trióxido de enxofre das amostras foi determinada conforme ABNT NBR NM 16 (2012), aproveitando o passante da filtragem da determinação do resíduo insolúvel. Nesta solução foi acrescentada água destilada até completar o volume de $250 \mathrm{~mL}$ sendo aquecida até a ebulição. Com auxílio de uma pipeta foi adicionado, gota a gota, $10 \mathrm{~mL}$ de solução aquecida de cloreto de bário $\left(\mathrm{BaCl}_{2}\right)$ com concentração $0,1 \mathrm{~g} / \mathrm{mL}$, e mantido a ebulição por aproximadamente 15 minutos. A solução ficou em repouso, tampada, por 12 - 24 h em temperatura ambiente, filtrada com papel de filtração lenta e lavada com água quente até a eliminação dos cloretos.

Em cadinho previamente calcinado e pesado $(M 1)$ foi transferido o papel de filtro e queimado em um forno mufla a 800 $\pm 50^{\circ} \mathrm{C}$, com taxas de aquecimento de $2,5^{\circ} \mathrm{C} / \mathrm{min}$, por 45 minutos. Após esfriar em dessecador, o cadinho foi pesado (M2), e a porcentagem de trióxido de enxofre $\left(\mathrm{SO}_{3}\right)$ foi calculada utilizando a Equação 10 , onde $M$ é a massa da amostra $(\mathrm{g})$; e $\mathrm{P}=34,3$ é o valor gravimétrico para transformar $\mathrm{BaSO}_{4} \mathrm{em} \mathrm{SO}_{3}$.

$$
\mathrm{SO}_{3}=\frac{\mathrm{M} 2-\mathrm{M} 1}{\mathrm{M}} . \mathrm{P}
$$

O óxido de cálcio livre nas amostras foi determinado pelo método do etileno glicol ABNT NBR NM 12 (2012). Para tal, $1,0000 \mathrm{~g} \pm 0,0100 \mathrm{~g}$ da amostra triturada foi colocado em um erlenmeyer de $125 \mathrm{ml}$, com algumas pérolas de vidro, adicionado $30 \mathrm{ml}$ de etileno glicol neutralizado, tampado com rolha de borracha e agitado por 1 minuto. A solução foi aquecida em banho 
de água, entre $65{ }^{\circ} \mathrm{C}$ e $70{ }^{\circ} \mathrm{C}$, por 30 minutos, sendo agitada de 5 em 5 minutos. Logo após, a solução foi filtrada em funil de Buchner, lavada 3 vezes com etileno glicol neutralizado, e aquecido entre $65^{\circ} \mathrm{C}$ a $70{ }^{\circ} \mathrm{C}$ utilizando $10 \mathrm{ml} \mathrm{de} \mathrm{cada} \mathrm{vez.} \mathrm{A} \mathrm{solução}$ foi titulada, sob agitação constante, com solução $0,1 \mathrm{~mol} / \mathrm{dm}^{3}$ de ácido clorídrico. $\mathrm{O}$ cálculo da porcentagem de $\mathrm{CaO}$ livre é dado pela Equação 11, na qual $F$ é o fator de correção da concentração do HCL, encontrado na padronização; $V$ é o volume de $\mathrm{HCl}$ gasto na titulação $(\mathrm{mL}) ; M$ é a massa da amostra $(\mathrm{g}) ; \mathrm{Fa}=0,002804$ é equivalente a $1 \mathrm{ml}$ da solução $0,1 \mathrm{~mol} / \mathrm{dm}^{3} \mathrm{de} \mathrm{HCl} \mathrm{em}$ $\mathrm{CaO}$.

$$
\text { CaO Livre }=\frac{F \cdot V \cdot F a}{M} .100
$$

O ensaio de determinação de finura por permeabilidade ao ar (método Blaine) foi realizado de acordo com a norma ABNT NBR 16372 (2015). Previamente foi calculado a massa do cimento a ser utilizada no ensaio, de acordo com a Equação 12, e a finura foi realizada no equipamento de Blaine, sendo calculado de acordo com a Equação 13, onde $M$ é a massa do cimento (g); $\rho$ é a massa específica $\left(\mathrm{g} . \mathrm{cm}^{-3}\right) ; \epsilon$ é porosidade de 0,5 como ponto de partida; $V_{\text {cam }}$ é o volume da camada de material determinado por aferição dada no aparelho; Blaine é a área específica $\left(\mathrm{cm}^{2} \cdot \mathrm{g}^{-1}\right) ; k$ é a constante de calibração do aparelho $\left(\mathrm{Pa}^{1 / 2} \cdot \mathrm{cm}^{-1}\right) ; T$ é o tempo de ensaio (s); $n$ é a viscosidade dinâmica do ar (Pa.s).

$$
\begin{gathered}
M=\rho \cdot \operatorname{Vcam}(1-\epsilon) \\
\text { Blaine }=\frac{K \cdot \sqrt{T} \cdot \sqrt{\epsilon^{3}}}{\rho \cdot(1-\epsilon) \cdot \sqrt{0,1 n}}
\end{gathered}
$$

Para a determinação da consistência da pasta de cimento foi utilizado a norma ABNT NBR 16606 (2017) e o equipamento de Vicat. Foi feito uma pasta com $500 \pm 0,10 \mathrm{~g}$ de cimento com quantidade aleatória de água, e obtido a consistência considerando os tempos de penetração Tetmajer, quando a mesma estacionar dentro do intervalo de $6 \pm 1 \mathrm{~mm}$. A consistência foi calculada segundo a Equação 14, onde $M 1$ é a massa da água (g) e $M 2$ é a massa de cimento (500 g).

$$
\text { Consistência }=\frac{M 1}{M 2} \cdot 100
$$

Os ensaios de tempos de pega foram realizados conforme a ABNT NBR 16607 (2017), sendo preparado uma pasta, cujo teor de água foi determinado de acordo com o ensaio de consistência, e colocado no equipamento de Vicat. Segundo Neville ( 2013) a pega refere-se a passagem da pasta de cimento de um estado de fluído para um estado rígido. A importância prática do ensaio é verificar se as adições de gesso estão nos teores pré-estabelecidos, uma vez que é este quem controla o fenômeno de pega. O perfil de endurecimento da pasta foi obtido utilizando a agulha de Vicat, que apresenta seção transversal de $1 \mathrm{~mm}^{2}$, o que, associado ao peso da haste de sustentação, promove uma pressão de $30 \mathrm{kgf} / \mathrm{cm}^{2}$. Realizando sucessivas penetrações a partir do Tempo $=0$, pode-se obter a curva de penetração. Definiu-se o início de pega quando a distância da agulha e a placa base contendo o cimento foi de $4 \pm 1 \mathrm{~mm}$.

Para determinar o fim de pega, o molde cheio de cimento foi invertido sobre sua placa base, e no mesmo aparelho de Vicat utilizando agulha de fim de pega, sendo efetuadas várias penetrações até que a agulha não penetrasse mais na pasta.

O ensaio de expansibilidade de Le Chatelier foi realizado de acordo com a norma ABNT NBR 11582 (2016), na qual verifica anormalidade na pasta de cimento provocado pela adição de água. Nos cimentos com essa patologia pode existir aumento considerável de volume ao longo do tempo. As substâncias que podem provocar essas instabilidades são principalmente: a cal 
livre (óxido de cálcio não combinado), o sulfato de cálcio em dosagens muito acima da necessária para regularizar o tempo de pega, e o óxido de magnésio cristalizado (periclásio).

Essa expansibilidade foi medida utilizando agulha de Le Chatelier, em duas modalidades: em água fria (se há excesso de gipsita ou anidrido), ou em água quente em ebulição (se há quantidades ou estruturas de cal livre que possa provocar instabilidades de volumes acentuadas). A expansibilidade a quente foi a diferença do último afastamento determinado e o primeiro afastamento, medido com auxílio de um paquímetro na base da agulha de Le Chatelier, sendo a leitura dada em milímetros.

\subsection{Preparação e caracterização dos corpos de prova}

Foram preparadas argamassas conforme a norma ABNT NBR 7215:2019, na qual a composição de cimento, areia padrão e água segue a proporção de 1:3:0,48, conforme Tabela 2. As argamassas foram homogeneizadas em misturador mecânico planetário de 5 litros, com velocidade de rotação da pá de $285 \pm 10 \mathrm{rpm}$ e movimentação planetária de $125 \pm 10 \mathrm{rpm}$.

Tabela 2 - Composição das argamassas.

\begin{tabular}{lcc}
\hline \multicolumn{1}{c}{ Material } & $\begin{array}{c}\text { Quantidade } \\
(\mathrm{g})\end{array}$ & $\begin{array}{c}\text { Proporção } \\
\text { (traço) }\end{array}$ \\
\hline Cimento Portland & $624 \pm 0,40$ & 1 \\
\hline Areia Normal - (Fração grossa) & $468 \pm 0,30$ & \\
\cline { 1 - 2 } Areia Normal - (Fração média) & $468 \pm 0,30$ & 3 \\
\cline { 1 - 2 } Areia Normal - (Fração média/fina) & $468 \pm 0,30$ & \\
\hline Areia Normal - (Fração fina) & $468 \pm 0,30$ & 0,48 \\
\hline Água & $300 \pm 0,20$ & \\
\hline
\end{tabular}

Fonte: Autores.

As argamassas foram moldadas no formato cilíndrico $(5 \mathrm{~cm}$ de diâmetro e $10 \mathrm{~cm}$ de altura), com a aplicação de 30 golpes de adensamento por camada, totalizando 4 camadas. Foram feitos 4 corpos de prova para cada composição de cimento, totalizando 528 unidades para o ensaio de compressão. Ainda nos moldes, os corpos de prova foram condicionados em câmara úmida com controle de temperatura de $\left(23 \pm 2^{\circ} \mathrm{C}\right)$, e pelo menos $95 \%$ de umidade relativa do ar onde permaneceram durante 24 horas para a cura inicial. Os corpos de prova foram desmoldados e colocados em tanque de cura com água saturada de cal, e retirados do banho para serem capeados, apenas nas suas respectivas datas de ensaio de resistência à compressão, ou seja, com $1,3,7,28,60,91$ dias.

O capeamento é indicado para evitar interferência na distribuição de cargas durante o ensaio de compressão, porque os corpos de prova apresentaram normalmente irregularidades nas faces. Os capeamentos dos corpos de provas foram feitos com uma mistura de enxofre e quartzo, na proporção de 67,5: 32,5 respectivamente, aquecido a uma temperatura de $136 \pm 7{ }^{\circ} \mathrm{C}$.

Para determinação da resistência à compressão utilizou-se a prensa Kratos, com célula de carga com capacidade de 100 tonelada força, modelo: CCI- série :5407. Para execução do ensaio seguiu a norma da ABNT BR 7215 (2019) que estabelece que cada corpo de prova, na idade especificada, fosse colocado sobre o prato inferior da prensa em perfeita centralização. O cálculo da resistência à compressão é dado pela Equação 15 , onde $R C$ é a resistência a compressão simples (MPa); $F$ é a força de ruptura do corpo de prova (N); e $S$ é a área de aplicação da carga $\left(\mathrm{mm}^{2}\right)$. Foi calculada a média das resistências individuais dos corpos de provas de mesma idade, considerando o desvio relativo máximo, ou seja, os valores dos desvios relativos que afastaram da média em mais de $6 \%$ foram excluídos. Os resultados foram comparados com dois cimentos referência para o cálculo do índice de desempenho: o cimento Portland comum (CPI) e cimento Portland de alta resistência inicial (CPV-ARI), utilizando a ABNT NBR 5732 (2018) e ABNT NBR 5733 (2018), respectivamente. 


$$
R C=\frac{F}{S}
$$

\section{Resultados e discussão}

\subsection{Tamanho de partícula das matérias primas e finura dos cimentos CFA e CFB}

O fíler de calcário B é um material com menor tamanho de partículas, sendo originário de um processo de moagem ultrafino, enquanto o filer de calcário A apresenta granulometria próxima ao clínquer e ao gesso utilizado, conforme Figura 2(a). Os cimentos CFA e CFB, Figura 2 (b), estão dentro dos especificados pela norma ABNT NBR 16697 que estabelece somente a peneira 200 mesh para controle.

De acordo com Lawrence, Cyr e Ringot (2003), a finura das adições influencia diretamente no desempenho mecânico do concreto. Quanto maior a superfície de contato cimento-água, maior quantidade de gel formado na hidratação e consequentemente maior resistência inicial. Porém, isso não quer dizer que a finura cria resistência, mas melhora a reação de hidratação do cimento. As partículas de cimento menores que a peneira 400 mesh $(0,038 \mathrm{~mm})$ se hidratam totalmente, enquanto as partículas de cimento retidas na peneira de 100 mesh $(0,149 \mathrm{~mm})$ não se hidratam; por mais longa que seja sua exposição à água não participam da resistência. Embora a finura seja favorável ao cimento, cabe salientar que processos de moagem geram um custo para a indústria.

Figura 2 - Distribuição granulométrica das matérias primas e dos cimentos CFA e CFB.

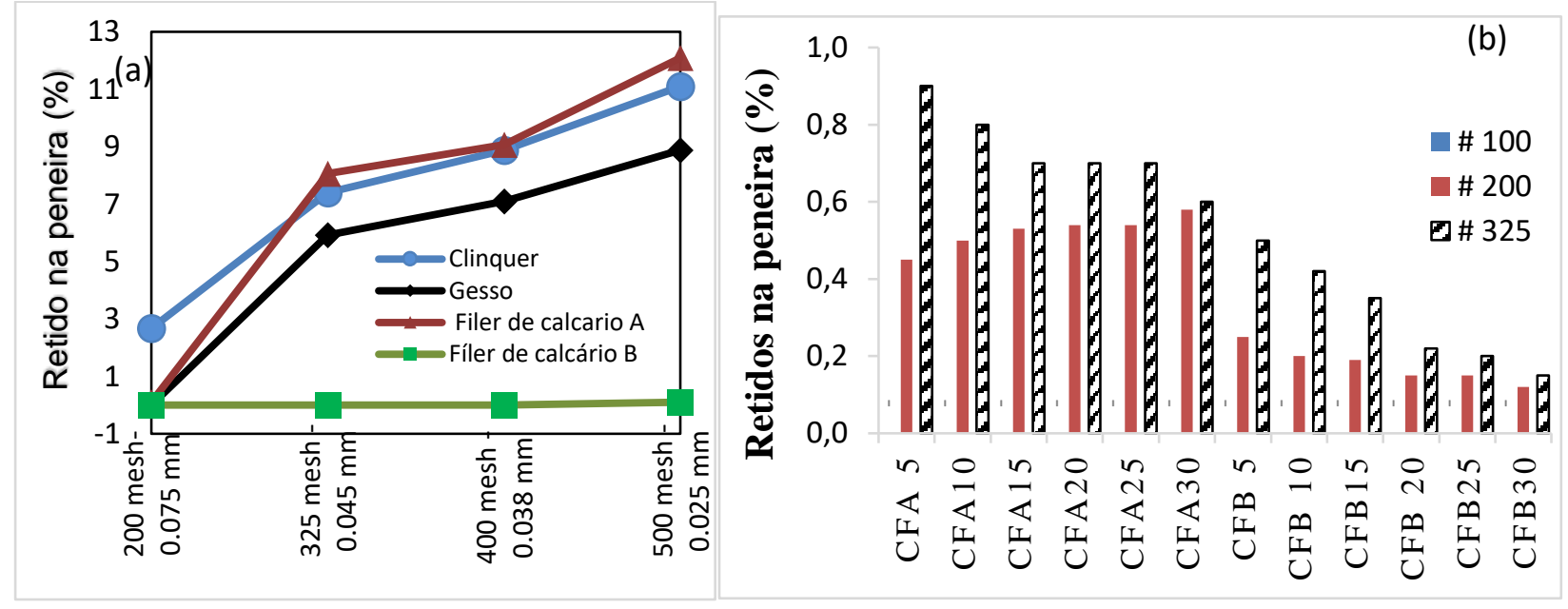

Fonte: Autores.

\subsection{Blaine (Superfície específica) e fator água/cimento}

Vários métodos são utilizados para determinar a superfície específica do cimento, todos segundo Neville (2013) baseados na lei de Stokes que relaciona a velocidade final de queda, pela ação da gravidade. Rigden e Blaine desenvolveram em 1940 um método para identificar superfície específica, que é comumente utilizado até hoje. Quando a área específica do composto cimentícios é aumentado, favorece a resistência nas primeiras idades (1 e 3 dias). Dois cimentos podem apresentar valores específicos de blaine iguais com perfil granulométrico diferentes (BUCHANAN, 1995) .O objetivo do ensaio Blaine, segundo a ABNT NBR 16372 (2015), é checar a uniformidade do processo de moagem, e analisar o potencial do cimento produzido em laboratório, para escala industrial. Para tal, foi utilizado a curva de moabilidade de Rittinger, que relaciona esforço útil realizado na moagem com a área superficial das partículas. Segundo a lei de Rittinger para calcular a área de uma nova superfície produzida utiliza-se a Equação 16, sendo $\mathrm{E}=$ =energia específica; $\mathrm{k}=$ fator de proporcionalidade; $\mathrm{S}_{1}=$ área do produto; e $\mathrm{S}_{0}=$ área inicial. Portanto, a quantidade de cimento produzida é diretamente proporcional ao seu diâmetro. 


$$
\mathrm{E}=\mathrm{K}\left(\mathrm{S}_{1}-\mathrm{S}_{0}\right)
$$

A Figura 3 mostra a simulação do desempenho de cada cimento de acordo com Blaine. Battagin (2011) observou uma tendência do aumento da área especifica nos cimentos que contém material carbonático, e com isso, a medida que aumenta a área específica dos cimentos, diminui a produção conforme os gráfico a da Figura 3. O cimento com maior produção é o cimento referência CFA5 que produz 80 toneladas em 1 hora. No outro extremo, a amostra CFB30 reduziu severamente a tonelada produzida de cimento, fato justificado com aumento da área específica devido a utilização de fíler micronizado.

Segundo Gerwick .JR (1982) elevado fator de água cimento é um dos causadores de danos a argamassas de cimento ou concreto, pois eleva bruscamente a sua permeabilidade. No Brasil, para produzir as argamassas de cimento de acordo ABNT NBR 7215 (2019) utiliza a proporção 1:3 em massa de cimento : areia, sendo a relação água/cimento igual a 0,48 (Neville, 2013).

Figura 3 - (a) Produtividade dos cimentos CFA e CFB e (b) Fator água/cimento das argamassas.
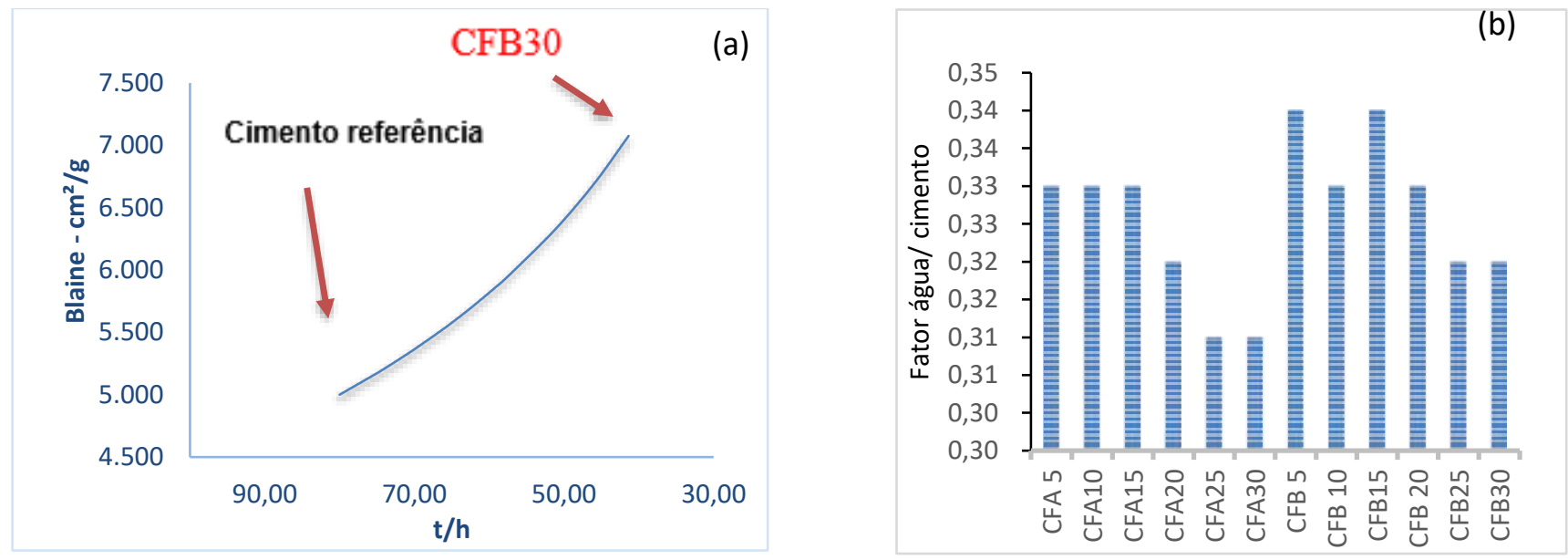

Fonte: Autores.

O perfil granulométrico influencia diretamente na relação fator água/cimento (Lothenbach et al., 2008), e na Figura 3(b) pode-se observar que quanto menor a granulometria (amostras CFB), maior quantidade de água será necessário para argamassa.

\subsection{Massa específica das matérias primas e dos cimentos CFA e CFB}

A massa específica do fíler calcário B é ligeiramente superior ao A (Tabela 3), corroborando ao seu menor tamanho de partícula. As massas específicas das adições minerais são inferiores à do clínquer, gerando cimentos com valores intermediários. A massa específica da maior parte dos cimentos brasileiros está compreendida no intervalo de 2,90 a 3,20 g/cm³ ABNT NBR 16605 (2017), o que corrobora aos resultados obtidos $\left(2,99-3,12 \mathrm{~g} / \mathrm{cm}^{3}\right)$. 
Tabela 3 - Massas específicas das matérias primas e dos cimentos CFA e CFB.

\begin{tabular}{lc|lc|lc}
\hline Matérias-primas & $\begin{array}{c}\rho \\
\left(\mathrm{g} / \mathrm{cm}^{3}\right)\end{array}$ & CFA & $\begin{array}{c}\rho \\
\left(\mathrm{g} / \mathrm{cm}^{3}\right)\end{array}$ & CFB & $\begin{array}{c}\rho \\
\left(\mathrm{g} / \mathrm{cm}^{3}\right)\end{array}$ \\
\hline Clínquer & 3,18 & CFA 5 & 3,11 & CFB 5 & 3,12 \\
Gesso & 2,33 & CFA 10 & 3,09 & CFB 10 & 3,11 \\
Fíler de calcário A & 2,69 & CFA 15 & 3,06 & CFB 15 & 3,09 \\
Fíler de Calcário B & 2,89 & CFA 20 & 3,04 & CFB 20 & 3,08 \\
& & CFA 25 & 3,02 & CFB 25 & 3,07 \\
& & CFA 30 & 2,99 & CFB 30 & 3,05 \\
\hline
\end{tabular}

Fonte: Autores.

\subsection{Composição química e perda ao fogo}

Os fíleres de calcário A e B possuem semelhanças nas características químicas (Tabela 4), apresentando majoritariamente óxido de cálcio $(\mathrm{CaO})$, e uma pronunciada perda ao fogo devido a decomposição do calcário liberando $\mathrm{CO}_{2}$, conforme Equação 17. A perda ao fogo do gesso $\left(\mathrm{CaSO}_{4} \cdot 2 \mathrm{H}_{2} \mathrm{O}\right)$ é oriundo da liberação de gases (SOx). O clínquer apresenta perda ao fogo insignificante porque a decomposição do calcário já ocorreu durante seu processamento. Desta forma, a incorporação do fíler de calcário na composição do cimento representa a redução do uso de clínquer e, consequentemente, a minimização de $\mathrm{CO}_{2}$ liberado para o ambiente, o equivalente a $40 \%$ da proporção de filer utilizado.

$$
\mathrm{CaCO}_{3} \underset{\Delta}{\rightarrow} \mathrm{CaO}+\mathrm{CO}_{2}
$$

Tabela 4 - Composição química das adições minerais e perda ao fogo experimental.

\begin{tabular}{|c|c|c|c|c|}
\hline \multicolumn{5}{|c|}{ Composição química e perda ao fogo $(\%)$} \\
\hline Óxidos & Clínquer & Gesso & Fíler calcário A & Fíler calcário B \\
\hline $\mathrm{SiO}_{2}$ & 19,50 & 1,12 & 2,87 & 1,50 \\
\hline $\mathrm{Al}_{2} \mathrm{O}_{3}$ & 4,19 & 0,52 & 0,12 & 0,10 \\
\hline $\mathrm{Fe}_{2} \mathrm{O}_{3}$ & 3,70 & 0,10 & 0,09 & 0,02 \\
\hline $\mathrm{CaO}$ & 62,80 & 33,18 & 54,24 & 54,00 \\
\hline $\mathrm{MgO}$ & 7,06 & 0,23 & 0,88 & 0,30 \\
\hline $\mathrm{SO}_{3}$ & 0,63 & 43,70 & 0,04 & 0,05 \\
\hline $\mathrm{Na}_{2} \mathrm{O}$ & 0,41 & - & 0,02 & 0,01 \\
\hline $\mathrm{K}_{2} \mathrm{O}$ & 0,58 & - & 0,08 & 0,10 \\
\hline $\mathrm{CaO}$ livre & 2,50 & & & \\
\hline $\mathrm{PFe}$ & 0,23 & 21,01 & 41,32 & 43,30 \\
\hline
\end{tabular}

Fonte: Autores.

Os compostos majoritários dos cimentos CFA e CFB são $\mathrm{CaO}$ e $\mathrm{SiO}_{2}$, apresentando respectivamente 58,0 a 60,30\% de $\mathrm{CaO}$ e 12,81 a 17,31\% de $\mathrm{SiO}_{2}$ (Tabela 5). Contudo, a norma ABNT NBR 16697 (2018) não especifica parâmetros para estes componentes. Os demais óxidos como $\mathrm{Na}_{2} \mathrm{O}, \mathrm{K}_{2} \mathrm{O}, \mathrm{P}_{2} \mathrm{O}_{5}, \mathrm{TiO}_{2}$ e $\mathrm{MnO}$ geralmente apresentam pequenos percentuais da massa de cimento. Mesmo minoritários, os compostos de $\mathrm{Na}_{2} \mathrm{O}$ e $\mathrm{K}_{2} \mathrm{O}$ recebem atenção pela possibilidade de reagir com outros agregados do concreto, e o produto dessa reação, chamado álcalis, pode causar desagregação.

De acordo com os resultados da Tabela 5, notou-se o aumento da perda ao fogo (experimental e teórica) com o aumento da proporção de fíler, como o esperado, por conta da decomposição do carbonato de cálcio. A perda ao fogo teórica foi calculada pela Equação 6. 
Tabela 5 - Composição química média dos cimentos CFA e CFB e perda ao fogo experimental e teórico.

\begin{tabular}{|c|c|c|c|c|c|c|c|c|c|c|c|c|}
\hline \multicolumn{13}{|c|}{ Composição química média dos cimentos e perda ao fogo (\%) } \\
\hline \multicolumn{7}{|c|}{ CFA } & \multicolumn{6}{|c|}{ CFB } \\
\hline & 5 & 10 & 15 & 20 & 25 & 30 & 5 & 10 & 15 & 20 & 25 & 30 \\
\hline $\mathrm{SiO}_{2}$ & 17,31 & 16,6 & 15,32 & 14,82 & 14,04 & 13,39 & 17,30 & 16,32 & 15,50 & 14,55 & 13,72 & 12,81 \\
\hline $\mathrm{Al}_{2} \mathrm{O}_{3}$ & 3,70 & 3,51 & 3,23 & 3,25 & 2,84 & 2,78 & 3,77 & 3,60 & 3,35 & 3,05 & 2,88 & 2,68 \\
\hline $\mathrm{Fe}_{2} \mathrm{O}_{3}$ & 3,30 & 3,10 & 3,02 & 2,83 & 2,55 & 2,37 & 3,30 & 3,08 & 2,96 & 2,69 & 2,49 & 2,31 \\
\hline $\mathrm{CaO}$ & 60,30 & 59,69 & 59,16 & 58,70 & 58,19 & 58,00 & 60,10 & 59,78 & 59,39 & 58,92 & 58,62 & 58,10 \\
\hline $\mathrm{Na}_{2} \mathrm{O}$ & 0,30 & 0,35 & 0,30 & 0,27 & 0,23 & 0,27 & 0,35 & 0,3 & 0,30 & 0,29 & 0,25 & 0,26 \\
\hline $\mathrm{K}_{2} \mathrm{O}$ & 0,51 & 0,50 & 0,45 & 0,49 & 0,42 & 0,40 & 0,49 & 0,49 & 0,42 & 0,41 & 0,40 & 0,37 \\
\hline $\mathrm{PFe}$ & 3,44 & 5,62 & 7,79 & 9,96 & 12,14 & 14,31 & 3,42 & 5,58 & 7,73 & 9,88 & 12,04 & 14,19 \\
\hline $\mathrm{PFt}$ & 3,45 & 5,64 & 7,83 & 10,02 & 12,21 & 14,40 & 3,45 & 5,64 & 7,83 & 10,01 & 12,21 & 14,40 \\
\hline
\end{tabular}

Fonte: Autores.

A Figura 4 mostra similaridade dos valores de PFe e PFt, de ambos cimentos, com CFA $\left(R^{2}=0,99\right)$ e $C F B\left(R^{2}=0,99\right)$. A perda ao fogo indica a extensão da descarbonatação, e as especificações estabelecidas pela norma NBR 16697 para os cimentos referência CPI e CPV limitou-se a perda ao fogo em 4,50 e 6,50\%, respectivamente. Para as especificações do cimento CPI comum somente as amostras de cimento CFA5 e CFB5 estão dentro do limite indicado, e para os cimentos CPV ARI RS as amostras de cimento CFA5, CFA10, CFB5 e CFB10. Contudo, os parâmetros estabelecidos para esses tipos de cimentos são considerados baixos, quando adicionado carbonatos na composição.

Figura 4 - Correlação da perda ao fogo experimental e teórica das amostras (a) CFA e (b) CFB.
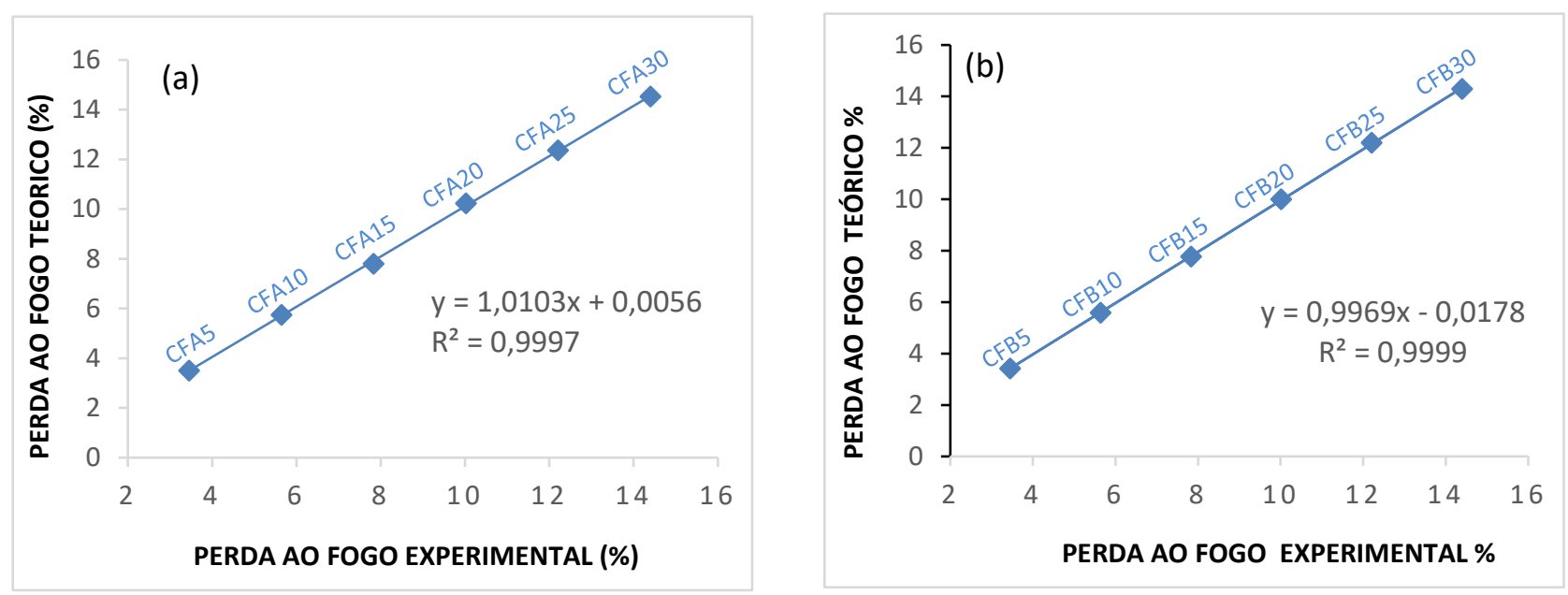

Fonte: Autores.

\subsection{Composto de Bogue}

A composição de Bogue, calculada a partir das Equações 1-4 e os resultados de FRX, foram: C3S = 63,77\%; C2S = 7,88\%; $\mathrm{C} 3 \mathrm{~A}=4,85 \% ; \mathrm{C} 4 \mathrm{AF}=11,25 \%$ e outros totalizando 12,25\%. Alita (C3S e Belita $(\mathrm{C} 2 \mathrm{~S})$ compreendem a maior proporção no clínquer, sendo que o $\mathrm{C} 3 \mathrm{~S}$ contribui com a resistência mecânica nas primeiras quatro semanas, e o $\mathrm{C}_{2} \mathrm{~S}$ influência no ganho de resistência final, podendo ocorrer em até um ano de cura (Neville, 2013). 


\subsection{Teor de trióxido de enxofre e resíduo insolúvel}

A determinação do tempo de pega tem uma grande importância para os usuários de cimento, pois com ele se tem o tempo necessário para trabalhar, transportar, lançar argamassas ou concretos, e pisar sobre ele. O controle da porcentagem de gesso no cimento é extremamente importante pois o excesso juntamente com o aluminato tricálcico $\left(\mathrm{C}_{3} \mathrm{~A}\right)$ pode formar o composto sulfo-aluminato tetracálcico ou sal de Candlot, e com isso, causar aparecimento rápido de expansão. Esse fenômeno pode ser observado nos primeiros dias de moldagem das argamassas ou concretos. A adição de gipsita durante a moagem do clínquer controla posteriormente o tempo de pega no cimento. Contudo, para cada tipo de clínquer há uma quantidade ótima de gesso a adicionar. Para esta pesquisa foi fixado o teor de gipsita em 5\% na moagem e estão de acordo com o que a NBR 16697:2018 que estipula o máximo de 4,5\% de teor de trióxido de enxofre no cimento, Figura 5(a).

Figura 5 - (a) Teores médios de trióxido de enxofre e (b) resíduo insolúvel nos cimentos CFA e CFB.
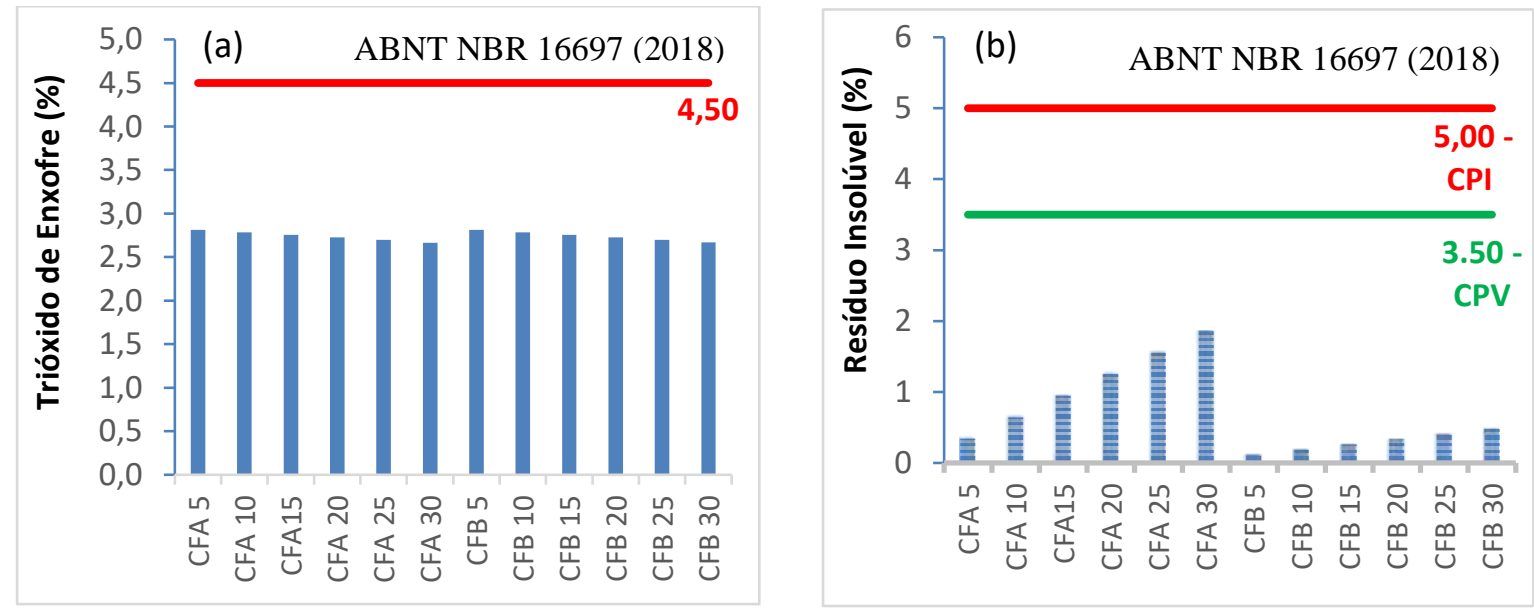

Fonte: Autores.

O teor de resíduo insolúvel foi determinado para verificar a presença de impurezas que não participam da reação, como metais na moagem do cimento. Pode-se observar na Figura 5(b) que maior porcentagem de fíler de calcário para os dos grupos CFA e CFB aumenta o resíduo insolúvel, devido sua natureza mineralógica de origem sedimentar.

\subsection{Teor de óxido de magnésio e expansibilidade}

Os cimentos CPI e CPV possuem 90\% de clínquer em sua composição, e o teor de óxido de magnésio deve ser limitado em 6,50\%, pois os clínqueres ricos em magnésio formam cristais de periclásio responsáveis por valores altos de expansão em autoclave. Isso ocorre devido a reação de hidratação do periclásio formando brucita que é acompanhado por um aumento de volume de $118 \%$. No caso dos cimentos produzidos neste trabalho, não apresentaram valores fora do especificados na ABNT NBR16697:2018. À medida que se adiciona fíler de calcário, o teor de magnésio diminui, devido a característica química do clínquer utilizado, que possui um certo teor de magnésio (Figura 6). 
Figura 6 - Teor de óxidos de magnésio nos cimentos CFA e CFB.

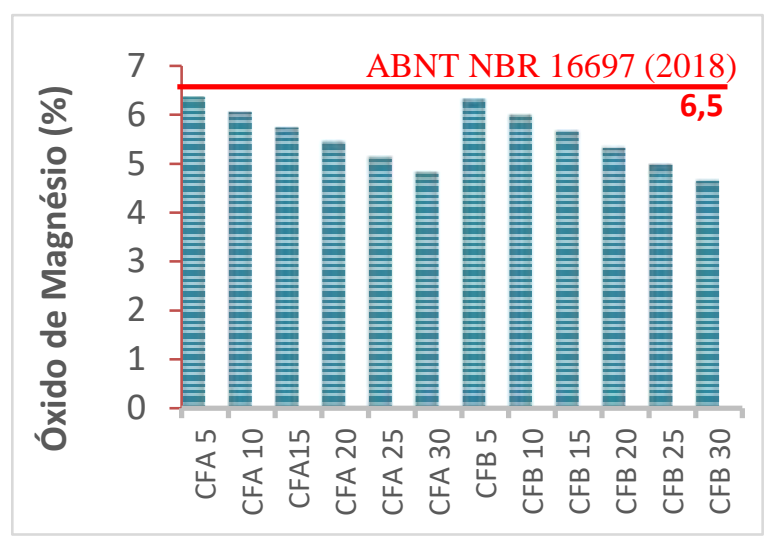

Fonte: Autores.

O ensaio de expansibilidade identifica instabilidade do volume de um cimento, durante e depois da hidratação. Os tipos de expansão com efeito deletério são ocasionados principalmente por $\mathrm{CaO}$ livre, $\mathrm{MgO}$ e $\mathrm{C}_{3} \mathrm{~A}$. Outro aspecto químico relevante relacionado ao aumento de fíler é a formação de portlandita $\left[\mathrm{CaO}(\mathrm{OH})_{2}\right]$ formado durante a hidratação de $\mathrm{C} 3 \mathrm{~S}$ e $\mathrm{C} 2 \mathrm{~S}$, que pode causar expansão no concreto (Gobbo, 2009). A Tabela 6 mostra a expansibilidade (medida com agulha Le Chatelier), CaO livre (calculada pela Equação 11), MgO (FRX), e C3A (calculada pela Equação 3).

Tabela 6 - Expansibilidade (E), teores de $\mathrm{CaO}$ Livre, $\mathrm{MgO}$ e $\mathrm{C}_{3} \mathrm{~A}$, expressos em porcentagem.

\begin{tabular}{lcccc}
\hline & E & CaO Livre & MgO & C3A \\
\cline { 2 - 5 } CFA5 & 0,00 & 2,22 & 6,40 & 4,30 \\
CFA10 & 0,50 & 2,17 & 6,16 & 4,07 \\
CFA15 & 0,50 & 2,00 & 5,85 & 3,84 \\
CFA20 & 0,50 & 1,88 & 6,28 & 3,62 \\
CFA25 & 0,50 & 1,70 & 5,05 & 3,39 \\
CFA30 & 0,50 & 1,60 & 4,89 & 3,16 \\
CFB5 & 0,50 & 2,20 & 6,33 & 4,30 \\
CFB10 & 0,50 & 2,22 & 5,99 & 4,08 \\
CFB15 & 0,50 & 2,08 & 5,66 & 3,85 \\
CFB20 & 0,50 & 1,95 & 5,32 & 3,63 \\
CFB25 & 0,50 & 1,81 & 4,98 & 3,41 \\
CFB30 & 0,50 & 1,70 & 4,65 & 3,18 \\
\hline
\end{tabular}

Fonte: Autores.

Os cimentos CFA e CFB apresentaram expansibilidade insignificante, e o teor de CaO livre e C3A diminuem com o aumento de fíler. Contudo, deve-se atentar que a expansão do $\mathrm{MgO}$ (periclásio) originário do clínquer desenvolve lentamente e o produto dessa reação chamado brucita - $\mathrm{Mg}(\mathrm{OH})_{2}$ hidrata-se com o tempo, não sendo perceptível no ensaio da agulha de Le chatelier.

A NBR 16697 estabelece o mínimo de 8,0\% de C3A no clínquer. Este constituinte é responsável pela pega, e o gesso é utilizado para a regulagem desse fenômeno, que retarda a hidratação dos constituintes de Bogue $\left(\mathrm{C}_{3} \mathrm{~S}, \mathrm{C}_{2} \mathrm{~S}\right.$ e $\left.\mathrm{C}_{3} \mathrm{~A}\right)$. Pode ocorrer a expansão por $\mathrm{CaO}$ livre, devido ao excesso de $\mathrm{C}_{3} \mathrm{~S}$ originário do clínquer, e também pelo excesso de fíler de carbonato. Vale ressaltar que cimentos que contêm $\mathrm{CaO}$ Livre menores que 1\%, não apresentam perigo de expansão. Porém, a hidratação do CaO Livre é um processo lento que pode durar além de 28 dias. 


\subsection{Consistência Normal}

A ABNT NBR 16607 (2017) define o tempo de início de pega como intervalo de tempo decorrido entre o momento em que o cimento entrou em contato com água, transformando-se em uma pasta plástica, até o momento em que começa a perder plasticidade. A norma estabelece o tempo mínimo de 60 minutos para os tipos de cimento e o fim de pega máximo de 600 minutos, sendo este último considerado facultativo. De acordo com a Figura 7 as amostras do grupo CFB foram as que obtiveram menores tempos de pega, devido ao perfil granulométrico.

Figura 7 - Resultados do tempo de início de pega.

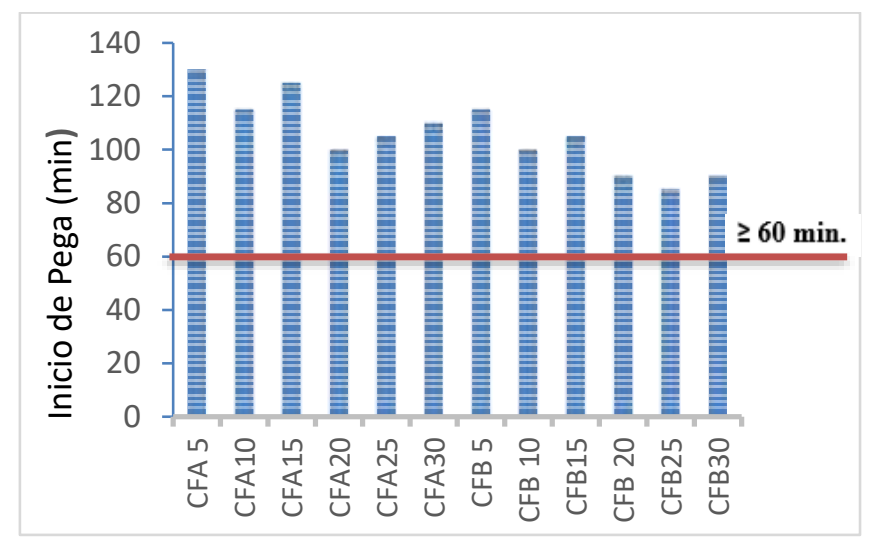

Fonte: Autores.

\subsection{Resistência à compressão}

A evolução das resistências à compressão dos corpos de prova de CFA em função da idade do ensaio pode ser visualizada na Figura 8. Com maior proporção de fíler de calcário a resistência à compressão diminui. Contudo, os resultados de CFA5 são maiores comparados à argamassa referência. Bonavetti, Rahhal e Irassar (2001), Lawrence, Cyr e Ringot (2003), Hoppe Filho (2008) e Aqel e Panesar (2016) mostram que com a utilização do fíler de calcário o cimento reage mais rapidamente, devido à sinergia das adições que melhora o grau de hidratação dos componentes de Bogue, resultando em maior resistência mecânica nas primeiras idades.

A norma NBR 16697:2018 indica três tipos de cimento, CPI 25, CPI 32 e CPI 40, que representa o mínimo de 25, 32 e $40 \mathrm{MPa}$ de resistência para a idade de 28 dias. Para CPI, a norma não regulamenta rompimento para 1 dia, somente para 3, 7 e 28 dias. Todos os cimentos CFA atenderam os respectivos valores de resistência para 3 e 7 dias, considerando a resistência relativa ao CPI 25, CPI 32 e CPI 40. Para 28 dias, os cimentos CFA atenderam os valores de resistência à compressão quando comparado ao CPI 25 e CPI 32, exceto a amostra CFA30 que não atingiu 32MPa. As amostras CFA não atingiram a resistência indicada para CPI 40, exceto a amostra CFA5, em 28 dias.

Comparando os cimentos CFA com o tipo CPV ARI RS, com base na NBR 16697:2018, todas as composições atingiram o mínimo indicado na norma (14 MPa) para a idade de 1 dia. No entanto, para a idade de 3 dias, observa-se que a composição CFA30 não atingiu a resistência necessária (24 MPa), porém o desempenho ficou muito próximo do exigido. Para idade de 7 dias, a maior parte das composições, exceto CFA5 e CFA10, não atingiram o mínimo que a norma estabelece para os cimentos do tipo CPV.

Na Figura 9 estão apresentados o índice de desempenho para os cimentos CFA, onde pode-se observar que CFA30 apresenta 66,39\% e 68,21\%, para 1 e 3 dias, indicando que não poderia ser enquadrado como tipo CPV ARI, pois não apresenta alta resistência inicial. Essa redução pode ser justificada pela elevada quantidade de fíler de calcário juntamente com a deficiência de óxido de silício. GOBBO (2009) analisou o grau de basicidade/acidez da escória de alto forno no sistema cimentício e concluiu 
que a relação $\mathrm{CaO} / \mathrm{SiO}_{2}$ determina a reatividade do cimento e reflete nos resultados de resistência a compressão, tanto nos primeiros como nos últimos dias. Caso essa relação, tender para o excesso de cálcio no sistema cimentício, a evolução da resistência é maior nos primeiros dias. Quando há excesso de sílica, que não é o caso de CFA30, a evolução da resistência é menor nos primeiros dias e maior nas idades 28,60 e 91 dias.

Figura 8 - Evolução da resistência à compressão dos cimentos CFA com a idade do ensaio.
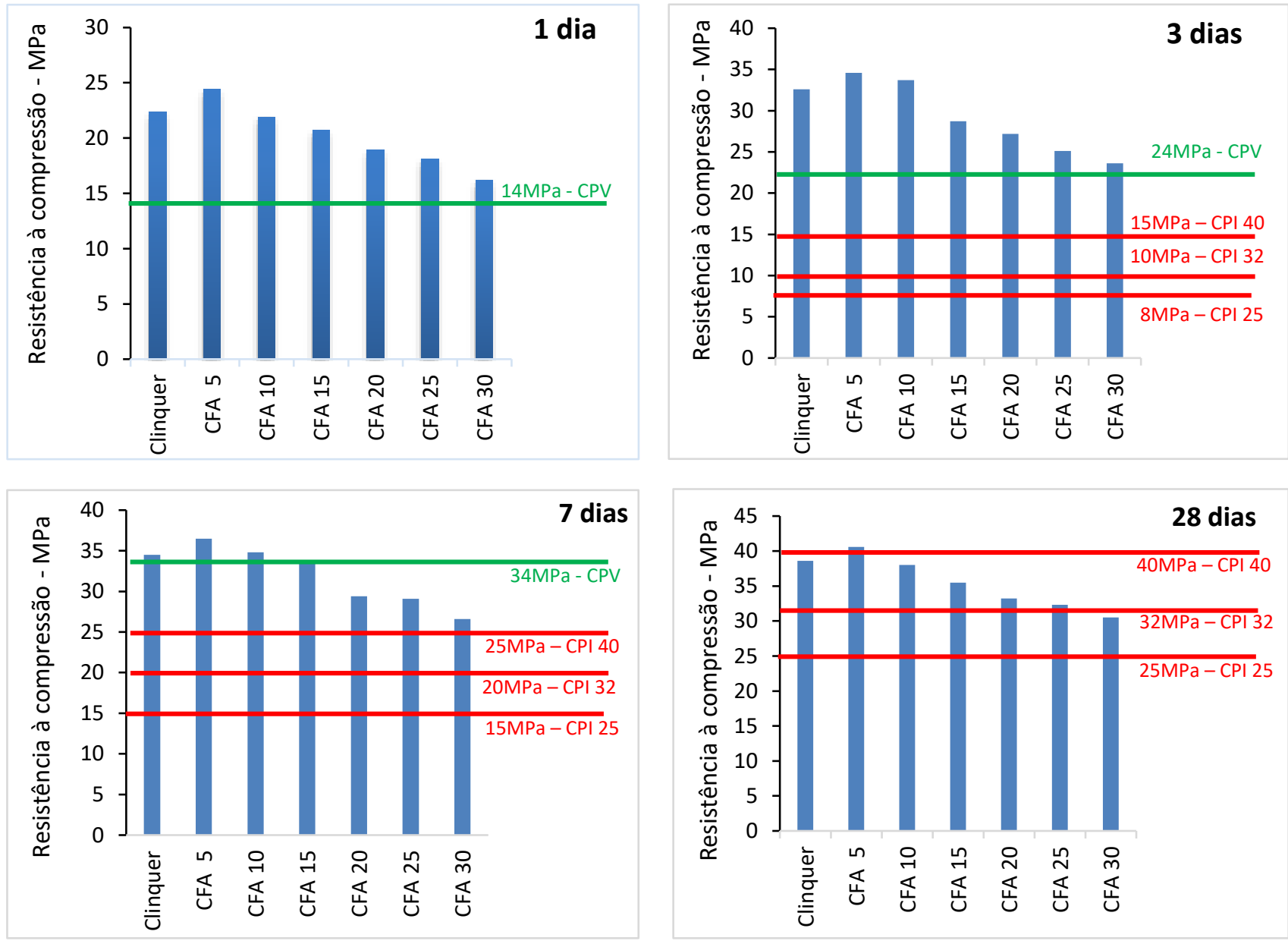

Fonte: Autores.

Figura 9 - Índice de desempenho dos cimentos CFA.

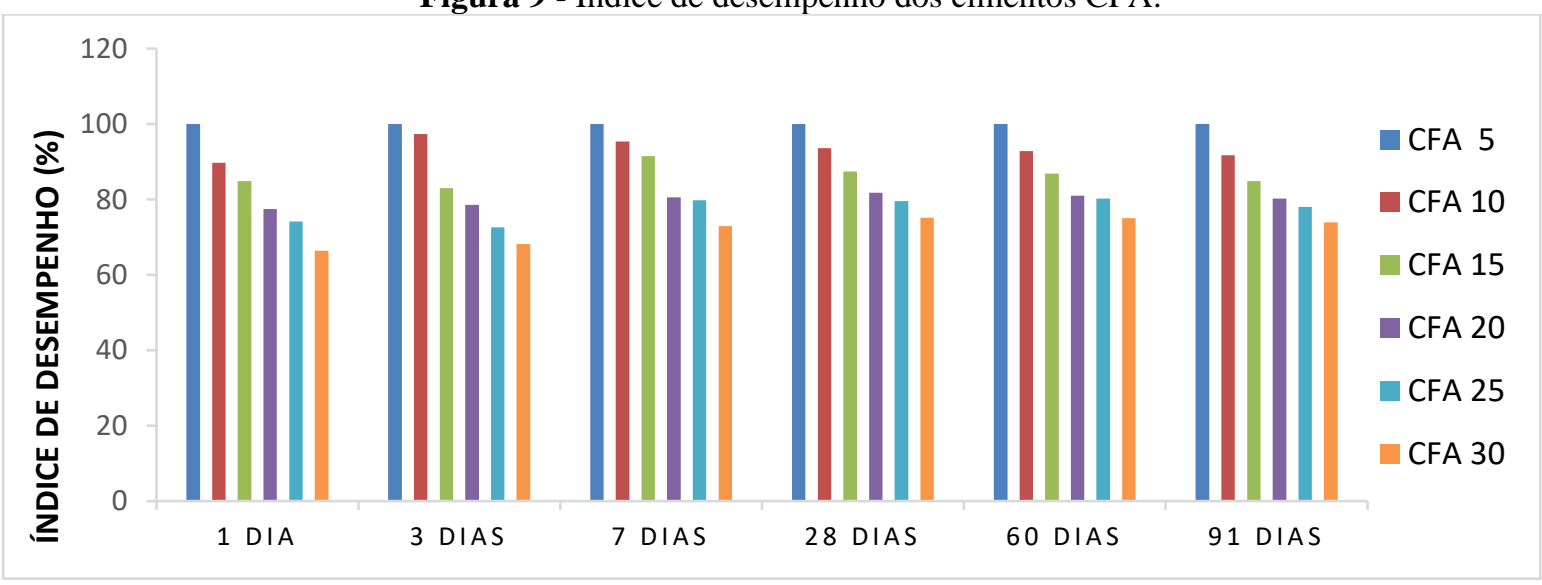

Fonte: Autores. 
Analisando os cimentos CFB, Figura 10, é possível verificar uma maior resistência à compressão nas idades de 1, 3 e 7 dias quando comparado com CFA, com todos os resultados superiores ao indicado na norma para cimentos CPI e CPV, e não apresentando uma tendência a declínio de resistência com o aumento da quantidade de fíler de calcário. Aos 28 dias, todos os cimentos CFB atenderam os valores de resistência à compressão considerando o tipo CPI 25, CPI 32, e os cimentos CFB5, CFB10 e CFB30 atenderam os padrões de resistência quando comparados ao CPI 40.

A adição de fíler de calcário com baixo grau de finura (CFA) influencia significativamente os valores de resistência à compressão, diminuindo principalmente a partir de $15 \%$ no clínquer. Mas para CFB, que possui maior finura, a resistência à compressão parece não diminuir com a quantidade de fíler, atendendo as propriedades considerando cimento CPI25, CPI32 e algumas composições de CPI40.

Figura 10 - Evolução da resistência à compressão dos cimentos do grupo CFB.

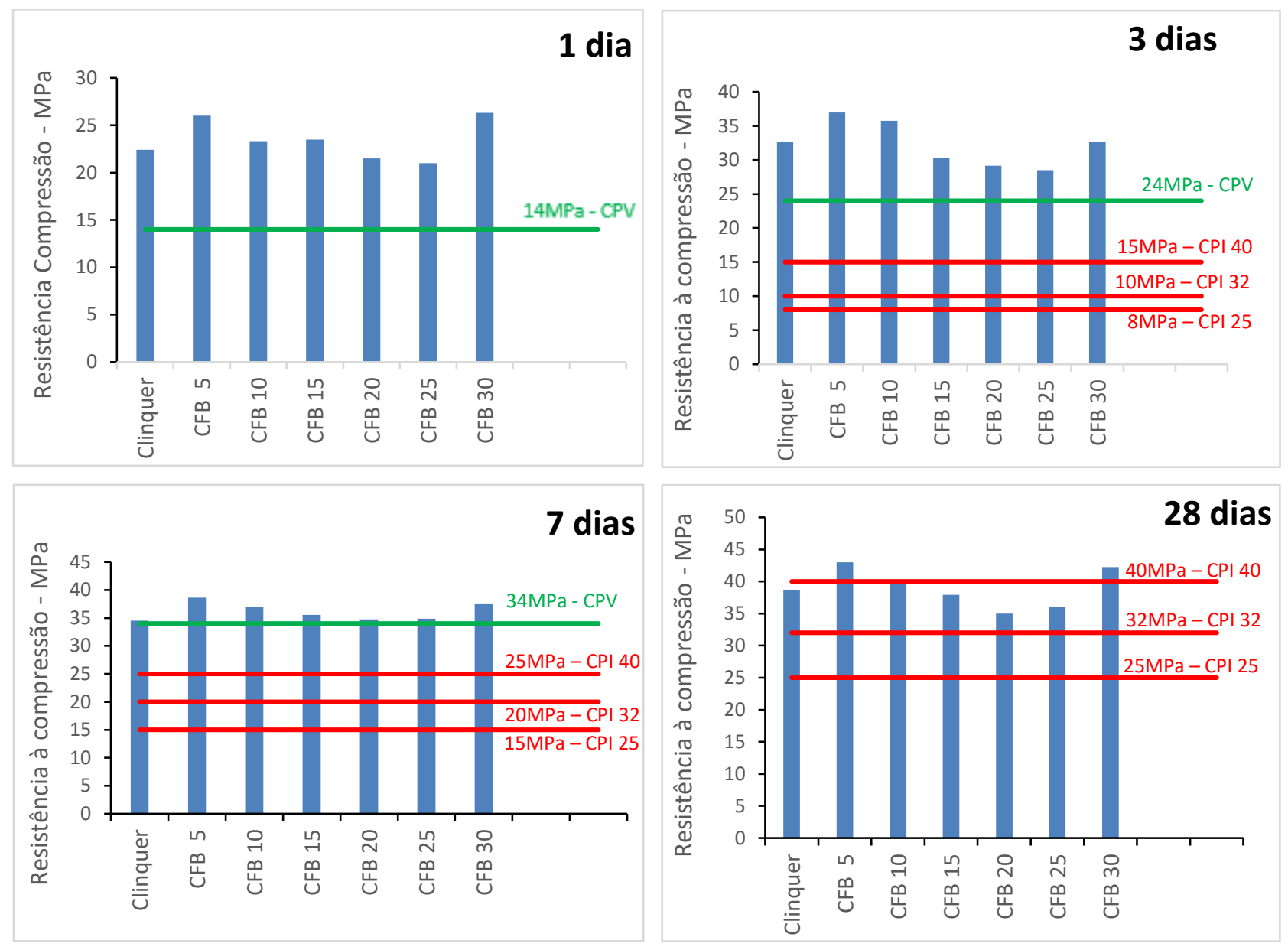

Fonte: Autores.

\section{Conclusão}

Tamanho de partícula do filer calcário B é menor que as demais matérias primas, e isso refletiu na granulometria das misturas CFB. A menor granulometria de CFB proporcionou uma maior relação água/cimento, e consequentemente pode aumentar a permeabilidade das peças.

A massa específica do filer calcário B é ligeiramente superior ao A, pois apresenta menor tamanho de partícula. Contudo, os valores médios das massas específicas obtidos $\left(2,99-3,12 \mathrm{~g} / \mathrm{cm}^{3}\right)$ compreendem a faixa indicada na NBR 16605 (2017). 
Os fíleres A e B possuem semelhanças nas características químicas, tendo majoritariamente $\mathrm{CaO}(\sim 54 \%)$ e uma pronunciada perda ao fogo $(\sim 42 \%)$ devido a decomposição do calcário. O gesso também contribui para perda ao fogo $(\sim 21 \%)$ causado pela liberação de SOx. Já o clínquer, não apresenta significativa perda ao fogo, pois já ocorrera durante seu processamento. Desta forma, a inserção de fíler de calcário contribui com mais de $40 \%$ para a minimização de gases poluentes no ambiente. Os cimentos CFA e CFB apresentaram perda ao fogo na ordem de 3,4-14,4\%, tanto para os valores experimentais quanto teórico, que são proporcionais às perdas dos constituintes individuais. Quando comparada a perda ao fogo de CFA e CFB, com os valores estabelecidos na norma para os cimentos tipo CPI, somente as amostras com $5 \%$ de fíler calcário atenderam, enquanto em comparação com cimentos tipo CPV - ARI, as amostras com 5 e 10\% estão dentro do especificado.

A quantidade de Alita (C3S) e Belita (C2S), calculadas pelas equações de Bogue, compreendem a maior proporção do clínquer utilizado ( 70\%), e estes influenciam diretamente na resistência mecânica inicial e final do cimento.

A quantidade de gesso utilizada nas misturas foi de 5\%, e é responsável pelo tempo de pega dos cimentos. O teor de $\mathrm{SO}_{3}$ de CFA e CFB foram similares ( 3\%), e estão dentro do estabelecido na norma. O ensaio de consistência mostrou que as amostras CFB foram as que tiveram menores tempos de pega devido ao perfil granulométrico, mas todos acima de 60 minutos, em conformidade com a norma.

O resultado de resíduos insolúveis de CFA e CFB também estão abaixo do estabelecido para cimentos CPI e CPV, no entanto, os valores aumentam com a quantidade de filer calcário. Cabe salientar que para CFB a porcentagem de resíduo insolúvel foi muito pequena, mesmo que para altas quantidades de filer calcário, indicando a possibilidade de que o método de ensaio utilizado não seja eficaz para baixas granulometrias.

$\mathrm{O}$ teor de óxido de magnésio, $\mathrm{CaO}$ livre e $\mathrm{C} 3 \mathrm{~A}$ contidos no clínquer podem interferir indiretamente na expansividade. Esses teores diminuíram com a adição de filer calcário para ambos cimentos, e os valores de expansividade foram insignificantes.

A adição de fíler de calcário tende a diminuir a resistência à compressão para as amostras de baixo grau de finura (CFA), no entanto não apresenta decaimento dos valores para cimento micronizado (CFB).

Portanto, pode-se concluir que a utilização de fíler calcário pode colaborar para a mitigação dos impactos ambientais provocados pelas indústrias cimenteiras, principalmente quando micronizado, pois altera positivamente várias características do cimento. No entanto, o custo para moagem do fíler calcário pode ser decisivo no processamento industrial.

Os autores estão dando continuidade ao estudo utilizando outros aditivos para comparação com o filer calcário, e verificar qual apresenta melhor desempenho no cimento, como forma de substituição de parte do clínquer. E como sugestão para trabalhos futuros tem-se a utilização de aditivos com baixo valor agregado ou resíduo de outro processo, que seja de fácil cominuição, e possibilidade de ser aglutinante como o clínquer, por exemplo os silicatos e aluminatos de cálcio e outros.

\section{Referências}

ABNT. (2016). NBR 11582. Cimento Portland - Determinação da expansibilidade Le Chatelier. Associação Brasileira de Normas Técnicas.

ABNT (2015). NBR 16372. Cimento Portland - Determinação da finura pelo método de permeabilidade ao ar (Método de Blaine). Associação Brasileira de Normas Técnicas.

ABNT (2017). NBR 16605. Cimento portland e outros materiais em pó - Determinação da massa específica. Associação Brasileira de Normas Técnicas.

ABNT (2017). NBR 16606. Cimento portland - Determinação da pasta de consistência normal. Associação Brasileira de Normas Técnicas.

ABNT (2017). NBR 16607. Cimento Portland - Determinação do tempo de pega. Associação Brasileira de Normas Técnicas.

ABNT (2018). NBR 16697. Cimentos Portland - Requisitos. Associação Brasileira de Normas Técnicas.

ABNT (2018). NBR 5733. Cimento Portland de Alta Resistência Inicial. Associação Brasileira de Normas Técnicas.

ABNT (2015). NBR 7214. Areia normal para ensaio de cimento - Especificação. Associação Brasileira de Normas Técnicas.

ABNT (2019). NBR 7215. Cimento Portland- Determinação da resistência à compressão. Associação Brasileira de Normas Técnicas. 
ABNT (2012). NBR NM 12. Cimento Portland-Análise química-Determinação de óxido de cálcio livre. Associação Brasileira de Normas Técnicas.

ABNT (2012). NBR NM 15. Cimento Portland - Análise química - Determinação de resíduo insolúvel. Associação Brasileira de Normas Técnicas.

ABNT (2012). NBR NM 16. Cimento portland - Determinação de trióxido de enxofre. Associação Brasileira de Normas Técnicas.

ABNT (2012). NBR NM 18. Cimento Portland - Análise química - Determinação de perda ao fogo. Associação Brasileira de Normas Técnicas.

ABNT (2010). NBR NM ISO 3310-1. Peneiras de ensaio - Requisitos técnicos e verificação parte 1: Peneiras de ensaio com tela de tecido metálico (ISO 3310 1,IDT). Associação Brasileira de Normas Técnicas.

Aqel, M., \& Panesar, D. K. (2016). Hydration kinetics and compressive strength of steam-cured cement pastes and mortars containing limestone filler. Construction and Building Materials, 113, 359-368. https://doi.org/10.1016/j.conbuildmat.2016.03.031

Battagin, A. F. (2011). Cimento Portland. Concreto: Ciência e Tecnologia, 1, 1-48.

Bonavetti, V. L., Rahhal, V. F., \& Irassar, E. F. (2001). 〈Bonavetti CCR01 limestone cement hydration.pdf〉. 31.

Buchanan, C. E. . (1995). New method for calculating grinding mill efficientes. In: International Conference On Cement Microspy, 17,.

CEMBUREAU. (2019). The european cement association. the role of cement in the 2050 low carbono economy.

Cervo, Amado L.; Bervia, Pedro A.; Da Silva, Roberto. (2007) . Metodologia Científica. $6^{\mathrm{a}}$ ed. Pearson Prentice Hall.

Gerwick.Jr. (1982). Cracking-corrosion interaction in concrete exposed to marine environment. Concrete International: Design And Construction.

Gobbo, L. de A. (2009). Aplicação da difração de raios-X e método de Rietveld no estudo de Cimento Portland. https://doi.org/10.11606/T.44.2009.tde$23072009-144653$

Hoppe Filho, J. (2008). Sistemas cimento, cinza volante e cal hidratada: mecanismo de hidratação, microestrutura e carbonatação do concreto.

IEA/WBCSD. (2009). Cement Techology Roadmap 2009 - Carbon emissions reductions up to 2050.

International, I. E. A., \& Agency, E. (2011). Technology Roadmap for Cement. SpringerReference. https://doi.org/10.1007/springerreference_7300

Lawrence, P., Cyr, M., \& Ringot, E. (2003). Mineral admixtures in mortars. Cement and Concrete Research, 33(12), 1939-1947. https://doi.org/10.1016/s00088846(03)00183-2

Lothenbach, B., Le Saout, G., Gallucci, E., \& Scrivener, K. (2008). Influence of limestone on the hydration of Portland cements. Cement and Concrete Research, 38(6), 848-860. https://doi.org/10.1016/j.cemconres.2008.01.002

Nanocem. (2013). Cement, Concrete and Emissions.

Neville, A. . (2013). Tecnologia do Concreto (Bookman (ed.).

Ramezanianpour, A. A., Ghiasvand, E., Nickseresht, I., Mahdikhani, M., \& Moodi, F. (2009). Influence of various amounts of limestone powder on performance of Portland limestone cement concretes. Cement and Concrete Composites, 31(10), 715-720. https://doi.org/10.1016/j.cemconcomp.2009.08.003

Scrivener, K. L. (2014). Indian Concrete Journal. Options for the Future of Cement, 3(July), 959-960.

SNIC. (2019). Sindicato Nacional de Industria de Cimento.Mudanças Climáticas. 